\section{THE STATE OF OFF-PUMP CORONARY ARTERY BYPASS IN 2015 \\ To the Editor:}

Over the past few years, dedicated investigators have continued to deliver compelling data on the outcomes of off-pump coronary artery bypass grafting (OPCAB) compared with conventional on-pump grafting (cCABG). The trial known as DOORS (Danish On-Pump vs Off-Pump Randomization Study) ${ }^{1}$ reported a concerning decrease in 6-month graft patency with OPCAB, whereas the results of the CORONARY trial (Coronary Artery Bypass Grafting Surgery Off or On Pump Revascularization Study $)^{2}$ showed an increase in perioperative acute kidney injury with $\mathrm{cCABG}$ while confirming no difference in survival and kidney function at 1 year. Additional studies have raised legitimate concerns regarding incomplete revascularization. Although all of the new information is quite valuable, the implications for clinical practice are complex and require diligent scrutiny to enhance clinical application of OPCAB.

Recognizing the direct relationship between technologic advances in surgery and the development of OPCAB is crucial for understanding its current value. In the early 1900s, before cardiopulmonary bypass was a known technique, the original canine models for coronary bypass were validated using OPCAB by default. ${ }^{3}$ Considerable refinements led to its translation

\footnotetext{
The Editor welcomes submissions for possible publication in the Letters to the Editor section that consist of commentary on an article published in the Journal or other relevant issues. Authors should: - Include no more than 500 words of text, three authors, and five references. - Type with double-spacing. - See http://jtcs.ctsnetjournals.org/misc/ifora.shtml for detailed submission instructions. - Submit the letter electronically via jtcvs.editorialmanager.com. Letters commenting on an article published in the JTCVS will be considered if they are received within 6 weeks of the time the article was published. Authors of the article being commented on will be given an opportunity of offer a timely response ( 2 weeks) to the letter. Authors of letters will be notified that the letter has been received. Unpublished letters cannot be returned.
}

into human patients, which was proven to be consistently effective by the 1970s. Concurrent headway in the development of cardiopulmonary bypass led to its widespread adoption because it offered a motionless operative field and better control over hemodynamics. ${ }^{4}$

By comparison, OPCAB was more difficult and therefore mainly set aside. Although the revival of OPCAB in the 1990s occurred in the context of advanced percutaneous therapy, the procedure was re-enlisted specifically for the purpose of ameliorating adverse consequences of the extracorporeal bypass circuit resulting from systemic inflammatory insult and multiorgan dysfunction theorized to result from microemboli. Moreover, this movement emerged as a direct result of innovations in tissue stabilizers and cardiac positioning devices that enabled dramatic improvement in operative exposure while maintaining hemodynamic stability, even in patients with limited cardiac reserve. In its technically simpler state, OPCAB became a viable alternative to prolonged anticoagulation, aortic cannulation, red blood cell trauma, and potential thrombotic emboli, with reduced costs and shorter hospital stays.

Unfortunately, many perceived benefits of forgoing cardiopulmonary bypass, though logical, have been inconsistently demonstrated. One well-substantiated view is that subpopulations of patients with coronary disease gain more from OPCAB than do others. In a recent example, the CORONARY trial $^{2}$ reaffirmed that transfusion requirements and perioperative bleeding decrease with OPCAB and further demonstrated that acute kidney injury and respiratory complications were significantly less likely than with cCABG. In addition, OPCAB is a well-known solution for severe aortic calcification and may reduce stroke rates in high-risk patients. ${ }^{5}$

Another important factor is the influence of surgeon experience on outcomes. This effect has been borne out in American, European, and Asian studies that enroll surgeons who perform high volumes of OPCAB. ${ }^{2,6}$ Further, in the setting of acute coronary syndrome, OPCAB has been found to maintain similar 30-day and 5-year survival compared with cCABG; it achieves, in addition, lower rates of reoperation for bleeding, and shorter operative times and hospital stays when performed by wellpracticed hands. ${ }^{7}$ On the other hand, the results of many trials and reviews have produced conflicting results, yet minimum OPCAB experience criteria sometimes remain relatively low.

Of rising concern is the possibility of limited graft patency with OPCAB, addressed recently by the DOORS trial. ${ }^{1}$ As other authors have suggested, the limitations of these data are significant. With nearly half of all angiography data missing, the risk of selection bias is very high. Furthermore, coronary angiography data collected at scheduled intervals, although indeed interesting, do not represent a patient-centered outcome. In fact, randomized controlled trials have repeatedly found similar rates of mortality and major adverse cardiac events with OPCAB compared with cCABG, leaving the utility of nonindicated angiographic data undefined. ${ }^{2,6}$ Because the primary goals of $\mathrm{CABG}$ are to increase survival and decrease symptoms and hospitalizations, interpretation of patency data is challenging.

A critical finding in the DOORS that was previously found in the Randomized On/Off Bypass (ROOBY) trial analysis ${ }^{8}$ is that the patency of left internal mammary artery (LIMA) to left anterior descending (LAD) coronary bypass has similar durability on and off pump. In addition, patients with LIMA-LAD bypasses have achieved similar outcomes with versus without complete revascularization of right coronary artery or left circumflex artery distributions. ${ }^{9}$ Reports of incomplete revascularization with 
OPCAB are by no means inconsequential; however, in the hands of experienced OPCAB surgeons, cardiac and survival outcomes have not shown clear indications of being negatively affected.

In fact, recent trends in coronary revascularization may be particularly amenable to OPCAB. Hybrid coronary revascularization, which implements a single LIMA-LAD bypass in conjunction with percutaneous coronary intervention, has been shown to produce similar 1-year survival and complication rates as CABG for multivessel disease. ${ }^{10}$ The use of multiple arterial conduits, which likely extends long-term survival by improving patency, offers a solution to the venous patency problem in OPCAB as well. ${ }^{11}$ Alternatively, LIMA-LAD bypass with sequential saphenous vein grafts shows no difference, compared with total arterial revascularization, in major adverse cardiac events or survival at 5 and 15 years. ${ }^{12}$ Lastly, improved intraoperative Doppler and transit-time flow-meter devices can confirm adequate anastomosis, potentially limiting the effects of the variability inherent in surgeon technique. ${ }^{13}$ In conclusion, OPCAB affords excellent clinical outcomes in experienced hands, and its utility as a less-invasive alternative to $\mathrm{cABG}$ continues to evolve within the burgeoning arena of surgical innovation.

Conor F. Hynes, $M D^{a}$ Gregory T. Trachiotis, $M D^{a, b}$ ${ }^{a}$ Division of Cardiothoracic Surgery Veterans Affairs Medical Center ${ }^{b}$ Division of Cardiothoracic Surgery The George Washington University Washington, DC

\section{References}

1. Houlind K, Fenger-Gron M, Holme SJ, Kjeldsen BJ, Madsen SN, Rasmussen BS, et al. Graft patency after off-pump coronary artery bypass surgery is inferior even with identical heparinization protocols: results from the Danish OnPump Versus Off-Pump Randomization Study. J Thorac Cardiovasc Surg. 2014;148:1812-9.

2. Lamy A, Devereaux PJ, Prabhakaran D, Taggart DP, Hu S, Paolasso E, et al. Off-pump or on-pump coronary-artery bypass grafting at 30 days. N Engl J Med. 2012;366:1489-97.

3. Carrel A. On the experimental surgery of the thoracic aorta and the heart. Ann Surg. 1910;52: 83.

4. Stoney WS. Evolution of cardiopulmonary bypass. Circulation. 2009;119:2844-53.

5. Marui A, Okabayashi H, Komiya T, Tanaka S, Furukawa Y, Kita T, et al. Benefits of off-pump coronary artery bypass grafting in high-risk patients. Circulation. 2012;126(11 Suppl 1): S151-7.

6. Diegeler A, Borgermann J, Kappert U, Breuer M, Boning A, Ursulescu A, et al. Off-pump versus on-pump coronary-artery bypass grafting in elderly patients. $N$ Engl J Med. 2013;368: 1189-98.

7. Emerson D, Hynes C, Greenberg M, Trachiotis G. CABG during acute coronary syndrome: outcomes and comparison of off-pump to conventional CABG at a Veterans Affairs Hospital. Innovations. 2015 [in press]

8. Shroyer AL, Grover FL, Hattler B, Collins JF, McDonald GO, Kozora E, et al. On-pump versus off-pump coronary-artery bypass surgery. $N$ Engl J Med. 2009;361:1827-37.

9. Rastan AJ, Walther T, Falk V, Kempfert J, Merk D, Lehmann S, et al. Does reasonable incomplete surgical revascularization affect early or long-term survival in patients with multivessel coronary artery disease receiving left internal mammary artery bypass to left anterior descending artery? Circulation. 2009;120(11 Suppl):S70-7.

10. Gasior M, Zembala MO, Tajstra M, Filipiak K, Gierlotka M, Hrapkowicz T, et al. Hybrid revascularization for multivessel coronary artery disease. J Am Coll Cardiol Cardiovasc Interv. 2014;7: 1277-83.

11. Glineur D, D'hoore W, Price J, Dorméus S, de Kerchove L, Dion R, et al. Survival benefit of multiple arterial grafting in a 25-year single-institutional experience: the importance of the third arterial graft. Eur $J$ Cardiothorac Surg. 2012;42:284-90; discussion 290-1.

12. Garatti A, Castelvecchio S, Canziani A, Corain L, Generali T, Mossuto E, et al. Long-term results of sequential vein coronary artery bypass grafting compared with totally arterial myocardial revascularization: a propensity score-matched follow-up study. Eur J Cardiothorac Surg. 2014;46:1006-13.

13. Trachiotis GD. Value of diastolic flow with transit-time flow meters in coronary artery bypass surgery. Eur J Cardiothorac Surg. 2011;39: 424-37.

http://dx.doi.org/10.1016/ j.jtcvs.2014.12.027

BENEFITS OF OPCAB ARE NOT FOR EVERYBODY. COSTS ARE. Reply to the Editor:

In the present issue of the Journal, Haynes and Trachiotis comment on recent literature regarding on-pump coronary artery bypass versus off-pump coronary artery bypass (OPCAB) surgery, including the data on graft patency from the Danish On-pump Versus Off-pump Randomization Study (DOORS).

It is correct when the authors claim that the angiographic follow-up data from the DOORS were not complete because only $56 \%$ of the surviving patients consented to have the examination performed. ${ }^{1}$ However, as pointed out in the accompanying editorial by Smith, ${ }^{2}$ an extensive statistical analysis was performed to ensure the balance of both perioperative and patient-related risk factors of graft occlusion. Therefore, we consider the observations to be valid. We confirmed the findings of a number of earlier investigators who found graft patency to be inferior. ${ }^{3,4}$ Even in smaller series performed by excellent OPCAB enthusiasts, ${ }^{5}$ there was a trend toward inferior graft patency after OPCAB, although the statistical power to conclude was not present. The number of grafts received by patients undergoing OPCAB is consistently lower than the number of grafts received by patients undergoing conventional coronary artery bypass grafting (cCABG) in most trials.

It is probably safe to assume that the majority of cardiac surgeons consider their own skills to be above average. Nevertheless, when performing an anastomosis, a bloodless, immobile field is an advantage in the hands of everyone, and even the surgeon who performs well without cardiopulmonary bypass is likely to perform even better when using it. It seems that with the current knowledge, the question that remains is not whether the grafts are better when performed with the use of cardiopulmonary bypass and cardioplegic arrest, but rather to which extent the advantage is clinically relevant and outweighs the risks.

In the DOORS, after 6 months follow-up, we found no significant difference between the OPCAB and 